\title{
Anti-proliferative effect of extremely low frequency electromagnetic field on preneoplastic lesions formation in the rat liver
}

Mónica Noemí Jiménez-García1, Jaime Arellanes-Robledo², Diana Ivette Aparicio-Bautista², Miguel Ángel RodríguezSegura', Saúl Villa-Treviño² and Juan José Godina-Nava*1

\begin{abstract}
Background: Recently, extremely low frequency electromagnetic fields (ELF-EMF) have been studied with great interest due to their possible effects on human health. In this study, we evaluated the effect of $4.5 \mathrm{mT}$ - $120 \mathrm{~Hz}$ ELF-EMF on the development of preneoplastic lesions in experimental hepatocarcinogenesis.

Methods: Male Fischer-344 rats were subjected to the modified resistant hepatocyte model and were exposed to 4.5 mT - $120 \mathrm{~Hz}$ ELF-EMF. The effects of the ELF-EMF on hepatocarcinogenesis, apoptosis, proliferation and cell cycle progression were evaluated by histochemical, TUNEL assay, caspase 3 levels, immunohistochemical and western blot analyses.

Results: The application of the ELF-EMF resulted in a decrease of more than $50 \%$ of the number and the area of $\gamma^{-}$ glutamyl transpeptidase-positive preneoplastic lesions $(P=0.01$ and $P=0.03$, respectively) and glutathione $S$ transferase placental expression $(P=0.01)$. The number of TUNEL-positive cells and the cleaved caspase 3 levels were unaffected; however, the proliferating cell nuclear antigen, Ki-67, and cyclin D1 expression decreased significantly $(P \leq$ $0.03)$, as compared to the sham-exposure group.
\end{abstract}

Conclusion: The application of $4.5 \mathrm{mT}$ - $120 \mathrm{~Hz}$ ELF-EMF inhibits preneoplastic lesions chemically induced in the rat liver through the reduction of cell proliferation, without altering the apoptosis process.

\section{Background}

Electromagnetic fields have been employed as useful tools in medical diagnosis. Recently, the use of electromagnetic fields has been expanded to therapeutic purposes because their interactions with living matter produce effects that initiate, accelerate or inhibit biological processes. Frequencies below $300 \mathrm{~Hz}$ are known as extremely low frequency electromagnetic fields (ELFEMF) and do not have enough energy to break molecular bonds; for example, they do not cause direct damage to DNA [1]. Additionally, ELF-EMF are non-invasive and non-ionizing and even have non-thermal effects on cells and tissues. These properties have led to studies of the

* Correspondence: jj@fis.cinvestav.mx

1 Department of Physics Center of Research and Advanced Studies of the National Polytechnic Institute, Mexico City, Mexico

Full list of author information is available at the end of the article influence of ELF-EMF on the development of various diseases, including cancer.

While some researchers associate ELF-EMF exposure with carcinogenesis [2,3], other studies of experimental models and human cancers have shown that ELF-EMF do not increase the risk of several cancer types, including liver cancer, and that treatment with tumor-specific frequencies is feasible and well tolerated and may have biological efficacy in patients with advanced tumors [4-6]. Moreover, the exposure of female $\mathrm{C} 3 \mathrm{H} / \mathrm{HeJ}$ mice bearing mammary adenocarcinoma to a frequency of $120 \mathrm{~Hz}$ at intensities of 4 and $5 \mathrm{mT}$ resulted in a significant reduction in the growth of the tumors, which is a phenomenon associated with angiogenesis inhibition [7]. The exposure of female athymic nude mice with human breast cancer xenografts to a frequency of $120 \mathrm{~Hz}$ with an intensity of $15 \mathrm{mT}$, either alone or in combination with gamma radiation, resulted in decreased growth and reduced vascular- 
ization of the tumors [8]. Similarly, the effect of $50 \mathrm{~Hz}$ at $0.5 \mu \mathrm{T}$ and $0.5 \mathrm{mT}$ on the development of chemically induced foci in rat livers showed a slight inhibition of their formation [9]. This evidence that ELF-EMF inhibit carcinogenesis is not convincing, and the exact molecular mechanisms that account for its effects must be validated. The purpose of this study was to use the modified resistant hepatocyte model (MRHM), which induces a rapid proliferation of altered hepatocytes to form preneoplastic lesions in the rat liver [10], as a reliable model to seek information concerning to the effects of ELF-EMF on hepatocarcinogenesis. We hypothesized that the development of preneoplastic lesions chemically induced in rat livers could be affected by $4.5 \mathrm{mT}-120 \mathrm{~Hz}$ ELF-EMF exposure. Our results showed that this exposure clearly inhibits the development of preneoplastic lesions through the reduction of cell proliferation, a characteristic alteration that has been found previously in the induction of experimental hepatocarcinogenesis [11,12]. Thus, our finding could be the basis for the design of strategies and clinical applications of ELF-EMF for the treatment of hepatocellular carcinoma.

\section{Methods}

\section{Reagents and antibodies}

N-Diethylnitrosamine (DEN), 2-acetylaminofluorene (2AAF), $\quad \gamma$-glutamyl-4-methoxy-2-naphthylamine (GMNA), glycyl-glycine and 4-benzoylamino-2,5diethoxybenzene-diazonium chloridae hemi [zinc chloride] salt (Fast Blue BB salt) were obtained from SIGMA (St. Louis, MO, USA). A DeadEnd ${ }^{\mathrm{mm}}$ Colorimetric TUNEL System kit was purchased from Promega (Madison, WI, USA), and a complete proteases inhibitor cocktail was acquired from Roche (Indianapolis, IN, USA). Anti-glutathione S-transferase placental (GST-p) and Universal $\mathrm{LSAB}^{\mathrm{m}}$ plus kit were obtained from DAKO (Carpinteria, CA, USA). Anti-PCNA and DAB Plus Substrate kit were purchased from Zymed (San Francisco, CA, USA). Anticyclin D1 was obtained from Bio SB (Santa Barbara, CA, USA), anti-Ki-67 was acquired from Cell Marque Corp (Austin, TX, USA), anti-caspase 3 was purchased from Cell Signaling (Danvers, MA, USA), and anti-actin was obtained from CINVESTAV, Mexico City.

\section{Experimental design}

Male Fischer-344 rats weighing 160 to $200 \mathrm{~g}$, obtained from the Production Unit of Experimental Laboratory Animals (UPEAL-CINVESTAV, México D.F., Mexico), were fed ad libitum and housed in a controlled environment (12 h light/12 h dark cycle; room temperature was maintained at $22 \pm 2^{\circ} \mathrm{C}$, with relative humidity at $55 \pm$ $10 \%)$. The experiments were performed in accordance with the guidelines of the Institutional Animal Care and Use Committee of the Official Mexican Standard NOM-
062-ZOO-1999. For carcinogenic treatment, MRHM was used $[11,13]$. The rats were initiated with a necrogenic dose of DEN (200 mg/kg of body weight, i.p.), and 7 days later, $2 \mathrm{AAF}$ was orally administered at $20 \mathrm{mg} / \mathrm{kg}$ per dose for 3 consecutive days before a partial hepatectomy $(\mathrm{PH})$ as shown Figure 1. Three groups of 6 rats each one, were randomized. The first group, which was used as the normal control did not receive treatment, NC group. The second group, which was used as the positive control for carcinogenesis, was subjected to the carcinogenic treatment and was kept under the same stress conditions without electromagnetic field exposure (sham-exposure) throughout the experiment; in this case the equipment was turned off, CT group. The third group, additionally to the carcinogenic treatment, was exposed to ELF-EMF according to "Animal exposure" section, CTF group. For this group, the administrations of DEN, 2AAF and $\mathrm{PH}$ were carried out before ELF-EMF exposure schedule. The animals were sacrificed on day 25 after carcinogenesis initiation (Figure 1). All of the rats from each group were used for all determinations. Biochemical and molecular evaluations were performed under blind conditions by expert people not involved in the animal exposure.

\section{System of ELF-EMF exposure}

A uniform and homogeneous ELF-EMF of $120 \mathrm{~Hz}$ was generated by a solenoid coil with 1900 turns in two layers and with AWG 20-gauge copper-enameled magnetic wire in a diameter of $25 \mathrm{~cm}$, which was driven by an alternating current source (Staco Variac variable transformer 511, ISE Inc; Cleveland, OH, USA). The equipment was controlled by a computer. The coil generated $0.1-4.5 \mathrm{mT}$ in its center, where the rats received the exposure. The magnetic flux density was measured using a Gauss/Teslameter (Hall effect gaussmeter F.W. BELL 5070, SYPRIS Test \& Mesurements; Orlando, FL, USA); the signal parameters were monitored by an inductive coil that was connected in parallel to a resistance by an oscilloscope (Tektronix TDS2024, TEKTRONIX Inc; Beaverton, OR, USA). The current flow was measured by an alternating current meter that was connected in series with the solenoid (Digital multimeter Tech TM-178, Techman Electronics Inc; La Verne, CA, USA). When the animals were exposed or had sham-exposure, the temperature inside the solenoid was monitored by a temperature sensor (LM35 IC: Integrated Circuit, National Semiconductor Corporation Americas; Santa Clara, CA, USA). The temperature sensor location and the shape of signal wave are shown in Figure 2.

\section{Animal exposure}

During the exposure, CTF group was divided in two subgroups of three rats each one and placed in a Plexiglas cage $(16 \times 16 \times 25 \mathrm{~cm})$ inside of solenoid. Each subgroup 


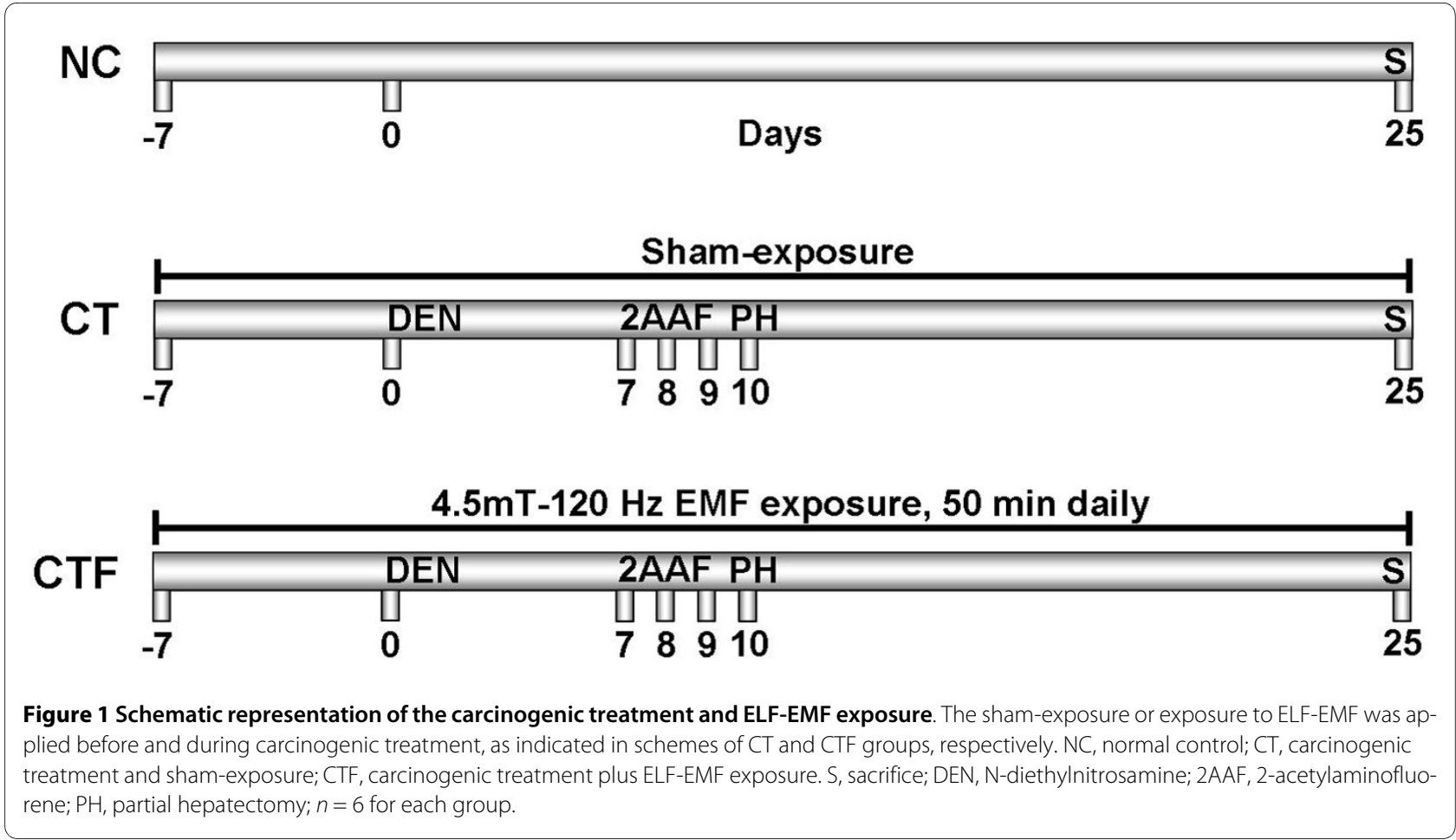

was exposed to $4.5 \mathrm{mT}-120 \mathrm{~Hz}$ ELF-EMF for $50 \mathrm{~min}$ daily as shown Figure 1; the first group was exposed from 10:00 - 10:50 $\mathrm{h}$ and the second was from 12:00 - 12:50 h, alternating them on this schedule, during 32 consecutive days (from 7 days before carcinogenic treatment until 25 days after). After exposure all animals were returned to their home cages. We decided to apply the ELF-EMF from 7 days before starting the carcinogenic treatment, because our initial approach was to assess its effect on the inhibition of preneoplastic lesions development in rat liver, as a strategy to prevent the disease in the early stages of its development.

\section{GGT histochemical staining}

Histological liver sections of $15 \mu \mathrm{m}$ were obtained in a cryostat (Slee Cryostat MTC, Germany). For each animal 3 tissue sections were analyzed randomly. The preneoplastic lesions in the rat livers were observed by the detection of $\gamma$-glutamil transpeptidase (GGT) activity as previously described [14]. Briefly, sections were fixed in absolute ethanol for $10 \mathrm{~min}$ at $-20^{\circ} \mathrm{C}$; the fixation was followed by the addition of GMNA, glycyl-glycine and Fast Blue BB salt in a $100 \mathrm{mM}$ Tris base for $30 \mathrm{~min}$ at room temperature. Subsequently, the staining was fixed with cupric sulfate for $2 \mathrm{~min}$. Finally, images of the liver tissue were captured with a digital camera in a microscope, and the GGT-positive lesions were quantified by image analysis software (analySIS Soft Imaging System GmbH). The experimental procedure was carried out at the same time for all comparative groups.
TUNEL assay and immunohistochemical analysis

Liver tissue sections, $4 \mu \mathrm{m}$ thick, were deparaffinized and hydrated gradually. DNA fragmentation was determined by a Colorimetric TUNEL System kit, according to the manufacturer's instructions and a tissue treated with DNase I was used as a positive control. For immunohistochemical analyses 4 sequential sections per rat were analyzed; antigens were unmasked by immersing the sections in $0.1 \mathrm{M}$ sodium citrate buffer $(\mathrm{pH} 6)$ in a heated water bath for $15 \mathrm{~min}$. Then, endogenous peroxidase activity was blocked with $0.3 \% \mathrm{H}_{2} \mathrm{O}_{2}$ in methanol. Primary antibodies anti-GST-p, anti-PCNA, anti-Ki-67 and anti-cyclin D1 were incubated overnight at $4^{\circ} \mathrm{C}$. After a standard staining protocol using Universal LSAB $^{\mathrm{ma}}$ plus kit and a DAB Plus Substrate kit as the chromogen, the sections were lightly counterstained with hematoxylin, dehydrated and mounted. As a positive control for PCNA, Ki-67 and cyclin D1, liver sections from one rat subjected to partial hepatectomy and sacrificed after 24 $\mathrm{h}$, were used to observe high proliferation levels. Tissues images were captured by optical microscopy (Olympus 1X70, Olympus Europa GmbH, Hamburg, Germany). Then, positive cells for PCNA, Ki-67 and cyclin D1 were quantified in ten randomly selected fields (magnification $10 \times$ ) per individual sample, and the numbers of positive cells $/ \mathrm{mm}^{2}$ were calculated using image analysis software (analySIS Soft Imaging System GmbH). For detection of each protein, the immunostaining protocol was carried out at the same time for all comparative groups. 


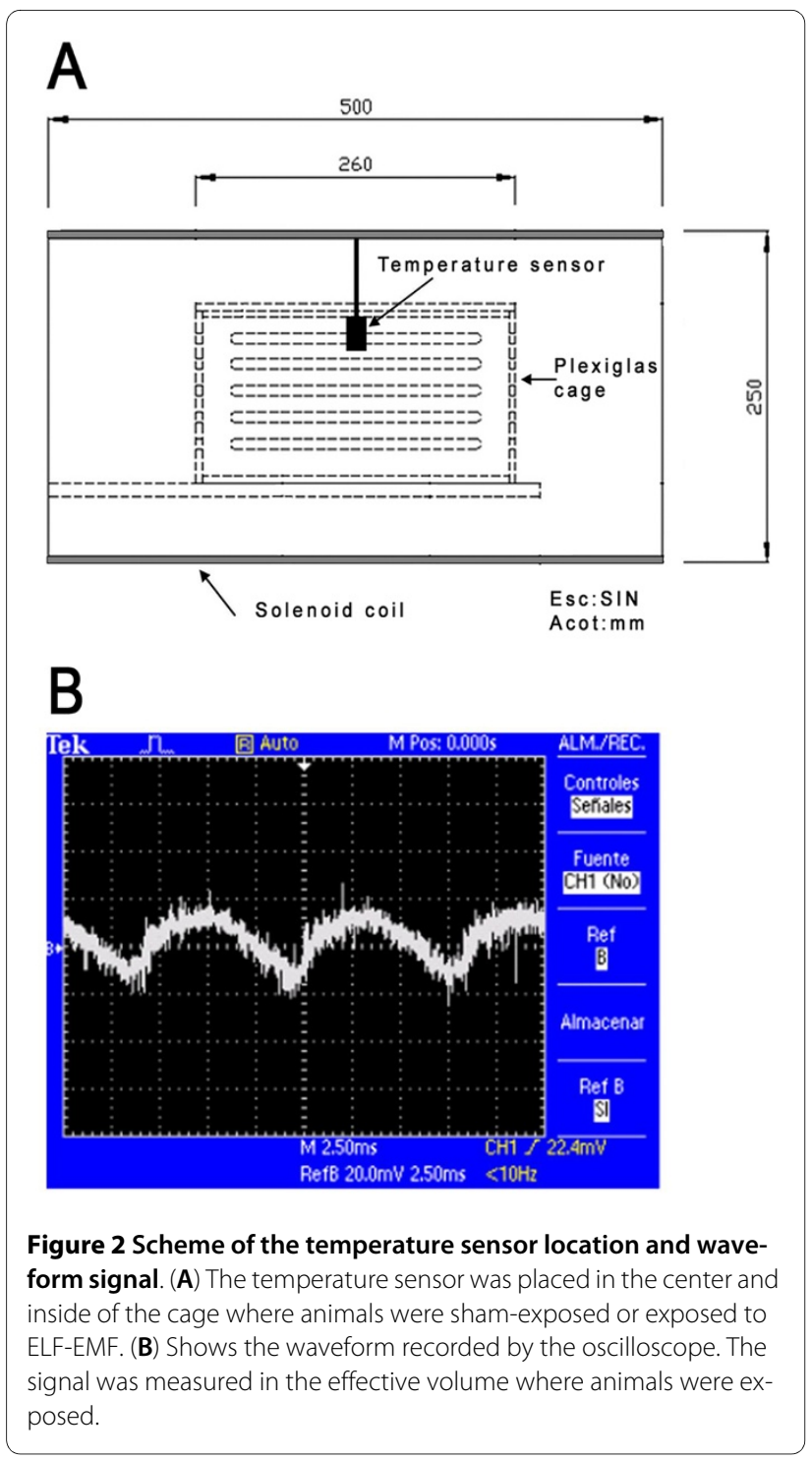

\section{Western blot analysis}

For proteins extraction, tissues were homogenized with lysis buffer (10 mM Tris-Cl pH 7.4, $150 \mathrm{mM} \mathrm{NaCl}, 1 \%$ Triton-X100 and proteases inhibitor cocktail), the cell lysates were centrifuged at $15,000 \mathrm{~g}$ for $30 \mathrm{~min}$, and the supernatant was stored at $-80^{\circ} \mathrm{C}$. The procedure was performed at $4{ }^{\circ} \mathrm{C}$. Proteins were separated by SDS-PAGE and were transferred to a PVDF membrane. The protein of interest was visualized using the indicated antibody and a chemiluminescence system. Anti-actin was used as a protein loading control.

\section{Statistical analysis}

Statistical differences were obtained between the carcinogenic treatment and the carcinogenic treatment plus electromagnetic field exposure using the Student's $t$-test. Data were expressed as the mean \pm the standard error of the mean (SEM). Differences were considered significant when $P<0.05$.

\section{Results}

\section{General observations}

The average body and relative liver weights of rats treated either with CT or CTF were not different throughout the experiment (data not shown). We also monitored the temperature of sham-exposure (CT) or exposure (CTF) groups during the 32 days and their values were recorded at specific times shown in Table 1 . The three degree differential temperature between the groups was due to the solenoid was turned off when the sham-group was exposed.

\section{ELF-EMF exposure inhibits preneoplastic lesions development}

Animals subjected to the CTF protocol showed a significant reduction in both the number and the area of GGTpositive lesions as compared to rats subjected to the CT protocol (Figure 3A). Table 2 shows the average value of foci number per $\mathrm{cm}^{2}$ and the percent of area GGT-positive of each animal subjected to different experimental protocols. The number and area of GGT-positive lesions were reduced by 52.2 and $58.4 \%(P=0.01$ and $P=0.03)$, respectively (Figure $3 \mathrm{~B}$ ). Similarly, western blot analysis (Figure 3C) showed that GST-p expression was reduced by $43.3 \%(P=0.01)$. These results indicate that the application of $4.5 \mathrm{mT}$ - $120 \mathrm{~Hz}$ ELF-EMF inhibits the development of preneoplastic lesions induced by the hepatocarcinogenesis experimental protocol.

\section{ELF-EMF exposure did not induce apoptosis}

To evaluate the effect of ELF-EMF exposure on the apoptosis induction of altered hepatocytes, we used two different procedures applied to the three groups. First, cells with DNA fragmented were identified in tissues by a TUNEL assay. Representative tissue sections of each treatment are depicted in Figure 4. Although a slight increase of TUNEL-positive cells is observed in the rat tissues of CT group (Figure 4C), these were not different from those of rats in the NC group or those in the CTF group (Figures 4B and 4D). According to this result, the levels of cleaved caspase 3 were not affected by either the $\mathrm{CT}$ or the CTF protocols as compared to the NC protocol (Figure 4E). These results indicate that the application of $4.5 \mathrm{mT}-120 \mathrm{~Hz}$ ELF-EMF does not induce either DNA fragmentation or the caspase- 3 activation, indicating that it does not promote apoptosis of altered hepatocytes.

\section{The application of $4.5 \mathrm{mT}-120 \mathrm{~Hz}$ ELF-EMF inhibits} proliferation during in vivo hepatocarcinogenesis

To determine whether the application of $4.5 \mathrm{mT}-120 \mathrm{~Hz}$ ELF-EMF had an effect on cell proliferation, which is a 
Table 1: Average values of the temperature recorded during the exposure time

\begin{tabular}{|c|c|c|}
\hline \multirow[b]{3}{*}{ Time/min } & \multicolumn{2}{|c|}{ Treatment group } \\
\hline & CT & CTF \\
\hline & $\mathrm{T} /{ }^{\circ} \mathrm{C}$ & $\mathrm{T} /{ }^{\circ} \mathrm{C}$ \\
\hline 0 & $23.7 \pm 0.4$ & $23.7 \pm 0.4$ \\
\hline 25 & $23.9 \pm 0.6$ & $25.8 \pm 0.6$ \\
\hline 35 & $24.2 \pm 0.6$ & $26.7 \pm 0.7$ \\
\hline 45 & $24.0 \pm 0.5$ & $27.1 \pm 0.6$ \\
\hline 50 & $24.1 \pm 0.6$ & $27.0 \pm 0.7$ \\
\hline
\end{tabular}

characteristic alteration from the induction of experimental hepatocarcinogenesis, we analyzed the expression of PCNA, which participates in replication and DNA repair, and the expression of $\mathrm{Ki}-67$, a specific replication marker, which participates in all active phases of the cell cycle except for the G0 phase. Moreover, PCNA and Ki67 are used to determinate the proliferating activity of cancer cells [15-17]. Figure 5 shows an immunohistochemical analysis of sequential sections of the same piece of liver tissue in which the expression of PCNA and Ki-67 proteins in GST-p-positive preneoplastic lesions can be seen. The positive labels of PCNA and Ki-67 were not limited to preneoplastic lesions; they were also detected in whole tissues of the rats subjected to the CT and CTF protocols. We observed, however, a clear reduction in the number of positively labeled cells, which was corroborated through a quantitative analysis, as shown in Table 3. The numbers of PCNA- and Ki-67-positive cells per $\mathrm{mm}^{2}$ were decreased in the CTF protocol as compared to the CT protocol by $87.88 \%(P=0.03)$ and $86.97 \%$ $(P=0.004)$, respectively. The nucleus labels of hepatocytes situated within the limits of the preneoplastic lesions for both the CT and CTF protocols were more intense. Figure 6 shows a western blot analysis that revealed a similar diminution of PCNA expression (53.62\%, $P=0.03$ ).

In order to determine the underlying mechanism of the proliferation inhibition mediated by the application of 4.5 $\mathrm{mT}-120 \mathrm{~Hz}$ ELF-EMF, we investigated the effect of this application on cyclin D1 expression, a cell cycle regulator protein responsible for the transition from G1- to Sphase in both normal regulation of the cell cycle and development of human cancers [18]. Thus, the coexistence of GST-p and cyclin D1 in serial sections of tissue was analyzed in a similar manner to that of the PCNA and Ki-67 expressions. As shown in Figure 5 and Table 3,

Table 2: Effect of ELF-EMF exposure on foci number per $\mathrm{cm}^{2}$ and the percent of area GGT-positive

\begin{tabular}{|c|c|c|c|}
\hline Group & \# animal & Foci number $/ \mathrm{cm}^{2}$ & $\%$ of GGT-positive area \\
\hline \multirow[t]{6}{*}{$\mathrm{CT}$} & 1 & $38.71 \pm 3.3$ & $6.93 \pm 0.4$ \\
\hline & 2 & $16.31 \pm 2.6$ & $2.27 \pm 0.5$ \\
\hline & 3 & $39.22 \pm 11.4$ & $5.63 \pm 1.2$ \\
\hline & 4 & $31.42 \pm 1.5$ & $12.76 \pm 0.8$ \\
\hline & 5 & $40.51 \pm 9.0$ & $8.77 \pm 1.7$ \\
\hline & 6 & $28.66 \pm 6.2$ & $4.98 \pm 1.1$ \\
\hline \multirow[t]{6}{*}{ CTF } & 1 & $0.65 \pm 0.6$ & $0.07 \pm 0.1$ \\
\hline & 2 & $8.13 \pm 3.5$ & $1.18 \pm 0.5$ \\
\hline & 3 & $27.45 \pm 5.7$ & $4.59 \pm 0.9$ \\
\hline & 4 & $14.85 \pm 2.6$ & $2.38 \pm 0.6$ \\
\hline & 5 & $24.40 \pm 2.2$ & $3.80 \pm 0.2$ \\
\hline & 6 & $14.50 \pm 2.5$ & $4.52 \pm 0.7$ \\
\hline
\end{tabular}

Values represent the mean \pm SEM of three liver sections evaluated per animal. 

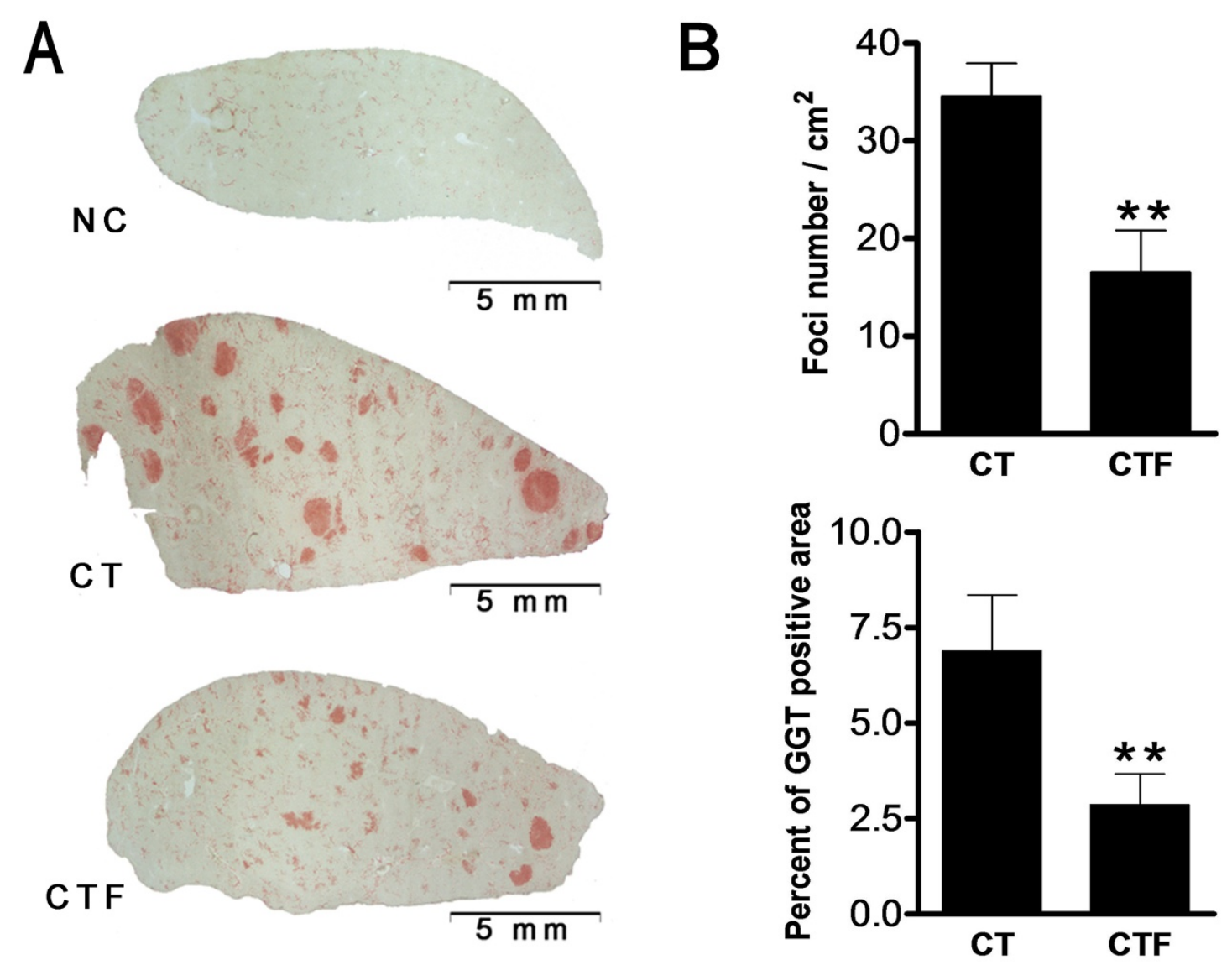

\section{C}
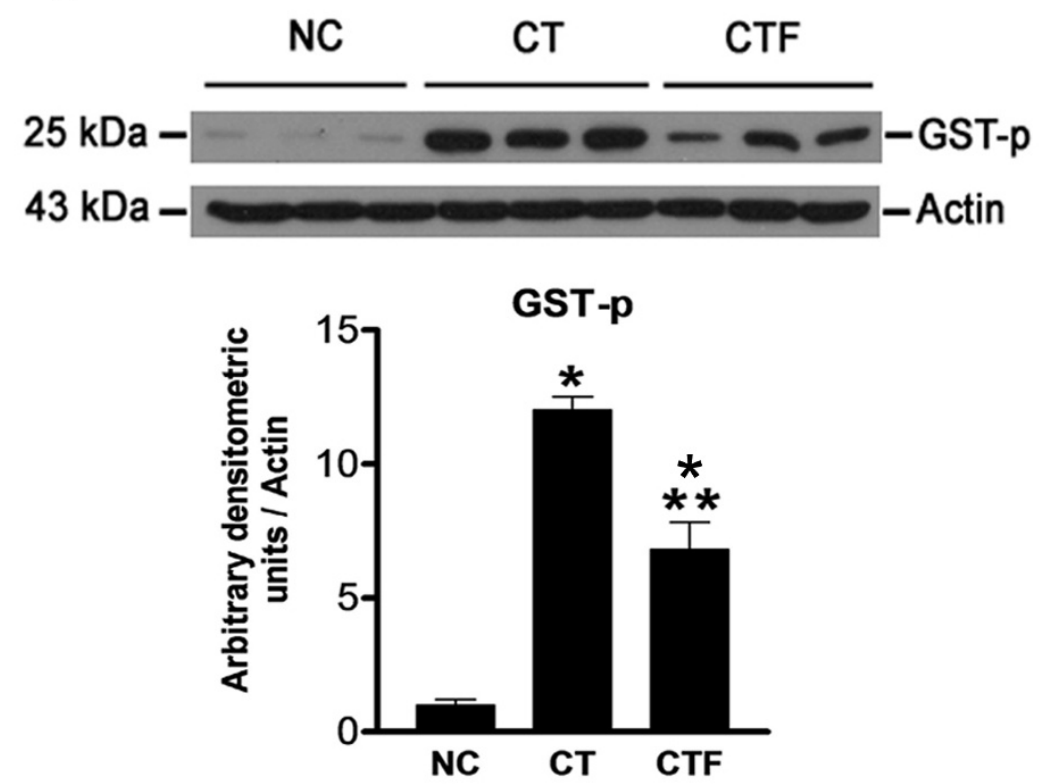

Figure 3 Effect of ELF-EMF exposure on GGT-positive lesions and GST-p expression. (A) Representative liver sections of the NC group, CT group and CTF group. Scale bars, $5 \mathrm{~mm}$. (B) Quantification of the foci number/cm² and percent of the GGT-positive area. (C) Western blot analysis for GST-p expression. GST-p was normalized with actin expression used as the loading control. The expression of NC was adjusted to one in the densitometric units scale. Statistically different from ${ }^{*} \mathrm{NC}$ and ${ }^{* *} \mathrm{CT}, P<0.05$. Data are expressed as the mean $\pm \mathrm{SEM} ; n=6$ for each group. 

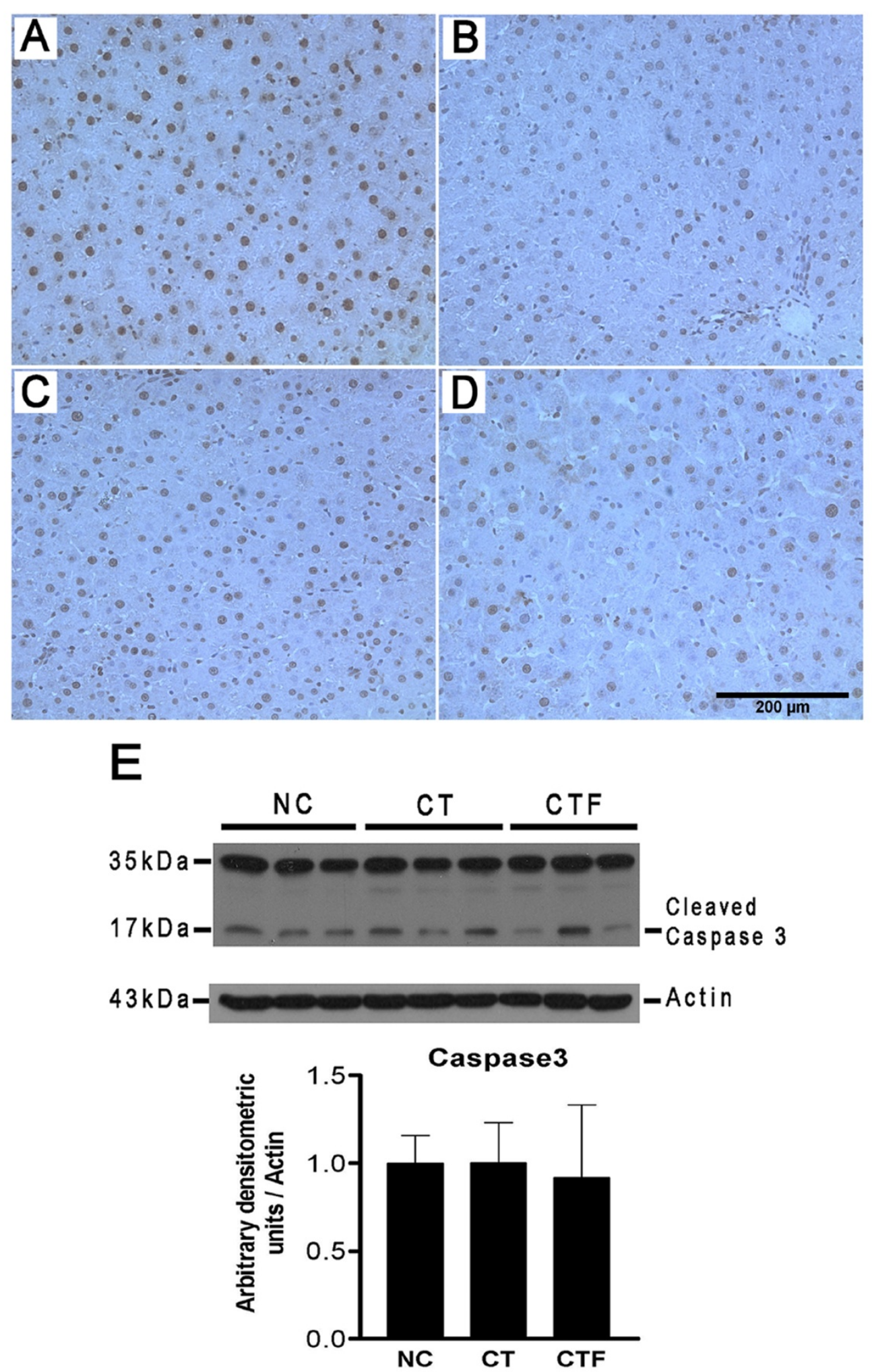

Figure 4 Effect of ELF-EMF exposure on apoptosis. Representative liver sections of each treatment are shown. (A) Positive control tissue that was treated with DNase I. (B) Normal control tissue. (C) CT protocol. (D) CTF protocol; images magnification 200x. (E) Western blot analysis for cleaved caspase 3 levels. Caspase 3 was normalized with actin expression used as the loading control. The expression of NC was adjusted to one in the densitometric units scale; $n=6$ for each group. 
Table 3: Number of PCNA-, Ki-67- and cyclin D1-positive cells/mm²

\begin{tabular}{cccc}
\hline & \multicolumn{2}{c}{ Cell number/mm2* } & \\
\cline { 2 - 4 } Treatment group & PCNA & Ki-67 & cyclin D1 \\
\hline NC & $22.36 \pm 1.05$ & $7.02 \pm 3.24$ & $49.31 \pm 2.07$ \\
CT & $492.03 \pm 76.36^{\mathbf{a}}$ & $192.74 \pm 15.49^{\mathbf{a}}$ & $265.39 \pm 23.95^{\mathbf{a}}$ \\
CTF & $59.59 \pm 10.38^{\mathbf{b}}$ & $25.11 \pm 3.32^{\mathbf{b}}$ & $44.75 \pm 5.36^{\mathbf{b}}$ \\
\hline
\end{tabular}

*Mean \pm SEM from ten fields per rat tissue, captured at 100 $\times$ magnification, $n=3$

aStatistically different from the NC group, $P<0.05$

bStatistically different from the CT group, $P<0.05$

the number of cyclin-D1-positive cells per mm2 was decreased for the CTF protocol as compared to the CT protocol by $83.13 \%(\mathrm{P}=0.008)$. Similar to PCNA and Ki67, cyclin D1-positive cells were observed in whole tissues of rats that were subjected to both the CT and CTF protocols. Figure 6 shows a western blot analysis that confirmed the decrease of the expression of cyclin D1 (53.43\%, $\mathrm{P}=0.01)$. Together, these results indicate that the inhibition of preneoplastic lesions development induced by the application of $4.5 \mathrm{mT}-120 \mathrm{~Hz}$ ELF-EMF in rat livers was associated with a reduction of cell proliferation and suggest that ELF-EMF protects hepatocytes from the increased proliferation induced by the carcinogenic treatment.

\section{Discussion}

Cancer cells manifest at least six main physiological alterations, which are governed by the deregulation of hundreds of genes that play a role in tumor initiation and progression and that collectively dictate malignant growth. One of the physiological alterations of cancer cells is their continuous growth; events associated with the increase in cell proliferation are the loss of apoptotic mechanisms and cell cycle continuity [19]. We have observed that, in the early hepatocarcinogenesis induced by the MRHM, cell proliferation is highly increased, which affects molecules that participate in cell cycle continuity and results in the formation of preneoplastic lesions that can progress toward hepatocellular carcinoma $[11,12,20]$. In this study, rats subjected to MRHM were exposed to $4.5 \mathrm{mT}-120 \mathrm{~Hz}$ ELF-EMF in order to evaluate the effects of the electromagnetic fields on the development of liver preneoplastic lesions. Our results showed that the $4.5 \mathrm{mT}-120 \mathrm{~Hz}$ ELF-EMF exposure significantly reduced both the number and the area of GGTpositive lesions and GST-p expression, which are two of the best markers for identifying preneoplastic lesions. We have validated this phenomenon, which has been observed previously, although only as a slight inhibition of the liver foci [9]. Although both studies involved hepa- tocarcinogenesis protocols, there are several differences in the waveform of their stimulus as compared to ours, such as the time of ELF-EMF exposure. Another important difference is that, in our model, the hepatocarcinogenesis treatment employed DEN, 2-AAF and $\mathrm{PH}$ without any additional intervention after $\mathrm{PH}$, whereas, in the protocol used by Rannug and coworkers, phenobarbital, a promoter of cell growth, was administered continuously throughout the 12 weeks of their experiment in addition to DEN and PH. It could be the case that the continuous promotion of altered cells in preneoplastic nodules counteracts the effects of the ELF-EMF, which resulted in a slight inhibition of the liver foci. In this work we clearly validated that ELF-EMF inhibits significantly the development of preneoplastic lesions. Even though the effects were significant, we observed a temperature differential between comparatives groups due to the solenoid was turned off when the sham-group was exposed; thus, we can not discard that this variable could has or not effect on the results. New experiments are required to determine this important fact.

Some authors have suggested the therapeutic use of ELF-EMF for cancer treatment because, in different experimental models, ELF-EMF have been able to inhibit the growth of cancer cell lines and tumors; however, few in vivo experiments have been performed to investigate the molecular mechanisms of ELF-EMF in cancer development [8,21-24]. The anti-carcinogenic effect of ELFEMF could result from the inhibition of cell proliferation and/or apoptosis induction. In vitro studies have reported the pro-apoptotic action of ELF-EMF and that this effect is associated with an increase in the number of annexin$\mathrm{V}$ - and TUNEL-positive cells and caspase 3 activity $[21,25]$. Previously, we observed that our hepatocarcinogenesis model does not induce apoptosis of altered hepatocytes evaluated at different points until 25 days after cancer initiation $[11,12]$. Using this model, we evaluated the pro-apoptotic effect of ELF-EMF exposure through TUNEL assays and cleaved caspase 3 levels, but we did not find any differences in the apoptosis status between 


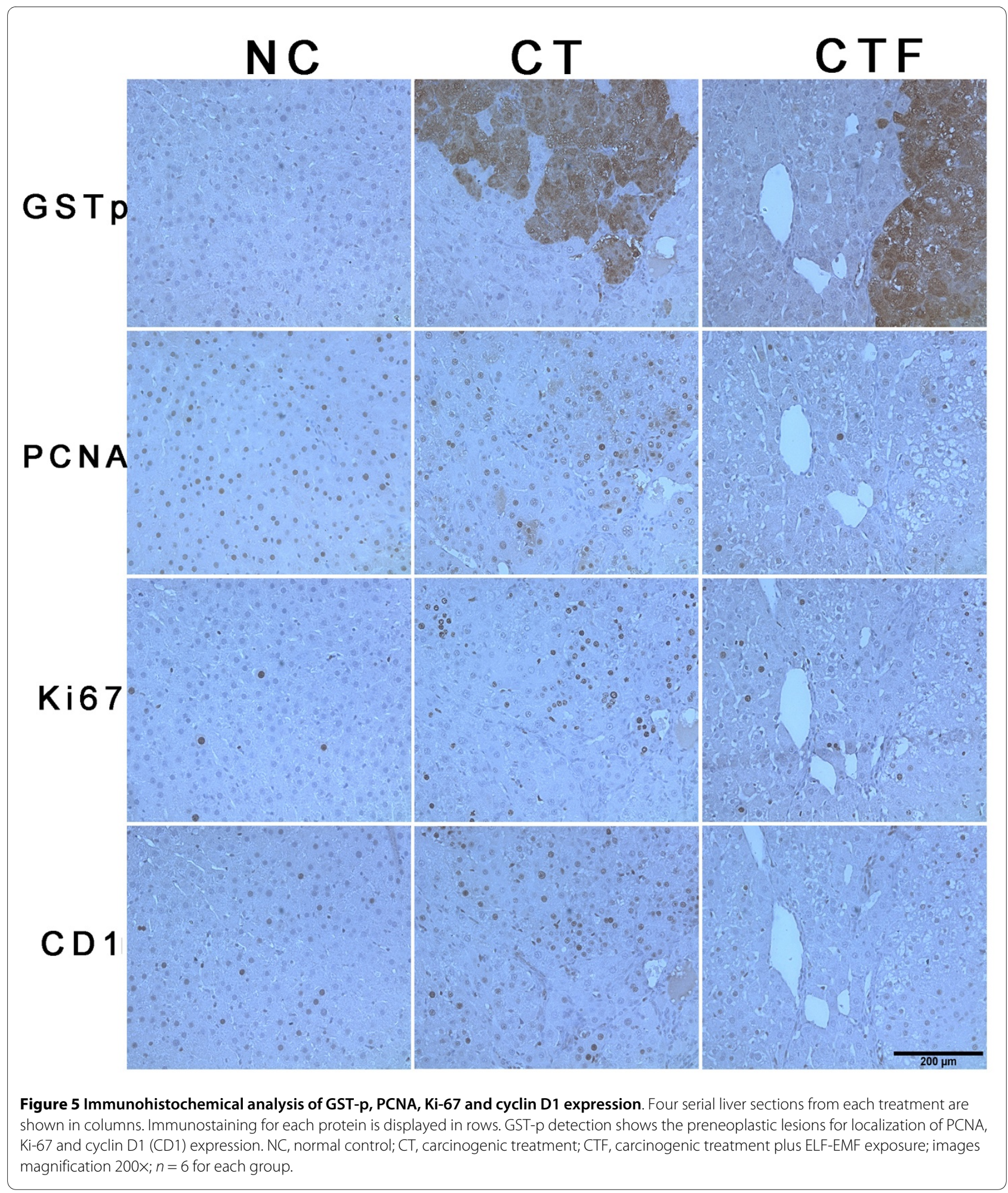

the CT and CTF groups. These data indicate that the application of $4.5 \mathrm{mT}-120 \mathrm{~Hz}$ ELF-EMF does not induce either DNA fragmentation or the caspase-3 activation, indicating that it does not promote apoptosis of altered hepatocytes.
During induction of liver cancer using the MRHM, the proliferation of hepatocytes increases; therefore, we tested whether $4.5 \mathrm{mT}-120 \mathrm{~Hz}$ ELF-EMF exposure affects the expression of PCNA, Ki-67 and cyclin D1. We showed that ELF-EMF exposure decreased the expression of these proteins, suggesting that the ELF-EMF 

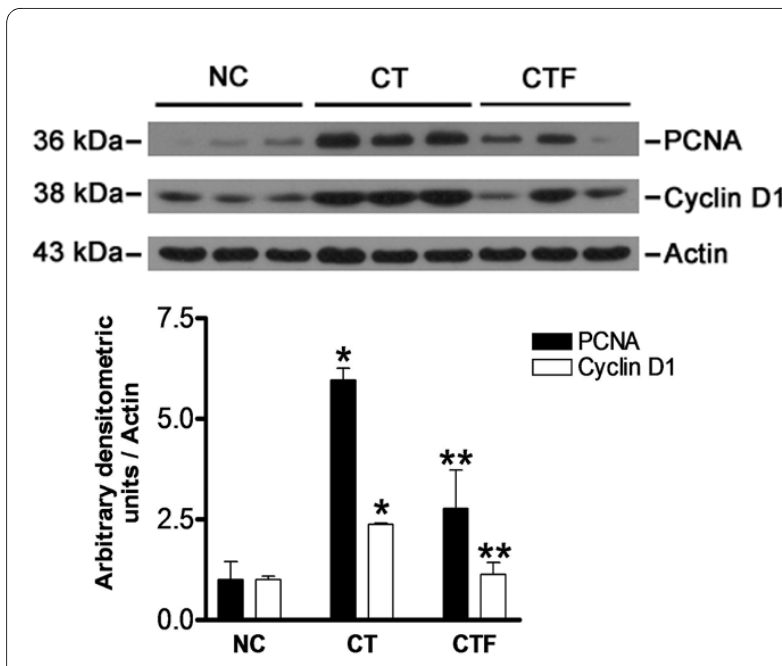

Figure 6 Effect of ELF-EMF exposure on PCNA and cyclin D1 expression. Western blot analysis for PCNA and cyclin D1 expressions. Both expressions were normalized with actin expression used as the loading control. The expression of NC was adjusted to one in the densitometric units scale. Statistically different from ${ }^{*} \mathrm{NC}$ and ${ }^{* *} \mathrm{C} T, P<0.05$. Data are expressed as the mean $\pm \mathrm{SEM} ; n=6$ for each group.

interferes with both the altered cell cycle continuity and DNA synthesis induced by chemical hepatocarcinogenesis. The effects on cyclin D1 expression and other proteins of the cell cycle have also been observed in human diploid amniotic fluid cells, where $1 \mathrm{mT}-50 \mathrm{~Hz}$ exposure diminished cyclin D1 expression though a significant cell arrest in the G2/M phase was induced when the electromagnetic field was applied in combination with different doses of ionizing radiation [26].

Since cells in liver preneoplastic lesions have a growth advantage as compared to the surrounding tissue, we also investigated whether PCNA, Ki-67 and cyclin D1 expressions were limited to the area of the lesions that were GST-p positive. We found that these proteins were expressed by cells from the whole tissue, including the preneoplastic lesions and surrounding tissue, although we found a significant reduction in the protein expression of tissues from rats subjected to the CTF protocol as compared to those of the CT protocol. Based on immunohistochemical analysis, the diminutions in the positive cells number for three proteins were more than $80 \%$. This effect was confirmed by western blot analysis for PCNA and cyclin D1 proteins where there was a reduction in the number of positive cells in more than $50 \%$. Together, these results show that $4.5 \mathrm{mT}-120 \mathrm{~Hz}$ ELF-EMF exposure affects the development of preneoplastic lesions of the liver and that this effect is associated with the inhibition of the proliferation process.

The correlation between the presence of Ki-67, PCNA and cyclin D1 has already been studied; while PCNA participates in replication and DNA repair and is also closely associated with the cell cycle machinery, Ki-67 is a specific replication marker associated with cell cycle entry given that participates in all active phases of the cell cycle except for the G0 phase $[15,16,27]$. We evaluated their expression by immunohistochemistry and found that ELF-EMF altered the amounts of positive cells expressing these proteins and we concluded that this effect is associated with the diminishing of cell proliferation. However, given that PCNA takes part else in DNA repair and that the amount of PCNA-positive cells were larger than Ki67 (see Table 3); if we assume that all Ki-67-positive cells were also PCNA-positive, it is striking to observe that from the subtraction between them ([PCNA - Ki67]), the number of remaining PCNA-positive cells is similar to the number of cyclin D1-positive cells. Thus, the remaining PCNA-positive cells would be involved in DNA repair, but not in proliferation processes. A similar analysis was reported in human myocytes, where was observed that TUNEL-positive cells can simultaneously express PCNA, but not Ki-67 [28]. This also could explain why the slight increase of TUNEL-positive cells observed in CT group, was not confirmed by cleaved caspase- 3 detection. Together this information, suggests that the ELFEMF could be altering the amount of cells bearing DNA damage in the MRHM model. Further studies are required to determine the nature of this possible association.

In our laboratory, we showed that the celecoxib, a nonsteroidal anti-inflammatory drug, inhibits the development of preneoplastic lesions through anti-proliferative mechanisms without inducing the apoptosis process [12], similar to the $4.5 \mathrm{mT}-120 \mathrm{~Hz}$ ELF-EMF exposure showed in this work. Even though celecoxib is a synthetic molecule and ELF-EMF is an interaction energy, both have anti-carcinogenic effects; however, when celecoxib is administered at high doses increases the risk of cardiovascular events [29]. Given the efficacy shown by ELFEMF exposure, our results motivate the evaluation of the synergic effect of ELF-EMF in combination with low doses of celecoxib, which could increase their efficacy and minimize the cardiovascular damage [30,31]; this combination of treatments could have an analogous result to the combination of low doses of X-ray or gamma radiation plus ELF-EMF exposure $[8,25]$.

ELF-EMF are able to interact with moving electrons and increase electron transfer rates in chemical reactions [32]. However, the interaction of ELF-EMF exposure with biological systems, from a physical point of view, remains unclear. Nevertheless, a biophysical model has recently been hypothesized. In this model, the action mechanism of the electromagnetic fields in cells occurs through the forced vibration of each of the free ions that exist on both sides of all plasma membranes and that can move across of them using transmembrane proteins, which disrupt 
the electrochemical balance of the plasma membrane and, therefore, the whole function of the cell [33]. Furthermore, evaluations in experimental models have been established that the electromagnetic fields are able to modulate the intracellular calcium $\left(\mathrm{Ca}^{2+}\right)$ when cellular homeostasis is disrupted [34]. Calcium is a highly versatile intracellular signal that can regulate many different cellular functions, whether normal or pathological; thus, the consequences of $\mathrm{Ca}^{2+}$ signaling depend of steady state between $\mathrm{Ca}^{2+}$ influx, efflux, and storage [35]. Cancer development takes place through rapid proliferation and the continuous increase of altered cells that modify the cellular environment [19], including the flow of ionic charges across the cell membrane, such as $\mathrm{Ca}^{2+}$ flow. Given that several blockers of $\mathrm{Ca}^{2+}$ entry inhibit tumor growth [36], we cannot discount that ELF-EMF could be regulating $\mathrm{Ca}^{2+}$ flow in the cells. Therefore, we can speculate that the interaction of ELF-EMF with ion flows in the membranes of altered cells interferes with processes that are involved in the development of liver preneoplastic lesions, such as the changes in cell cycle continuity induced by DEN, 2AAF and PH. Finally, another possible action mechanism of ELF-EMF could be at radical chemistry levels; in this way we currently are designing experiments to determine this possible effect on electron transfer rates involved in the oxidative stress generated throughout the chemical hepatocarcinogenesis progression and we are also making a quantum-mechanical model, using radical pairs mechanism theory, that could explain this process.

\section{Conclusion}

Our results indicate that the application of $4.5 \mathrm{mT}-120$ Hz ELF-EMF affects the early carcinogenesis chemically induced in rat livers, through the reduction of PCNA, Ki67 and cyclin D1 expressions without inducing apoptosis, which suggests that ELF-EMF regulate cellular homeostasis and inhibit the development of preneoplastic lesions. Finally, considering that hepatocellular carcinoma is a common form of cancer and that its incidence around the world remains high [37], this finding could be the basis for the design of strategies and clinical applications of ELF-EMF to treat this disease, aimed primarily at high-risk populations.

\section{List of abbreviations}

2AAF: 2-acetylaminofluorene; DEN: N-Diethylnitrosamine; ELF-EMF: extremely low frequency electromagnetic fields; GMNA: $\gamma$-glutamyl-4-methoxy-2naphthylamine; GGT: $\gamma$-glutamil transpeptidase; MRHM: modified resistant hepatocyte model; PH: partial hepatectomy; SEM: standard error of the mean.
Competing interests

The authors declare that they have no competing interests.

\section{Authors' contributions}

MNJG designed and performed the study and drafted the manuscript. JAR and DIAB participated in western blotting and immunohistochemical determinations and made substantial contributions to the study design. MARS designed the software and the electronic diagram of the electromagnetic field equipment. SVT and JJGN led and supervised the entire study. All the authors read and approved the final version of the manuscript.

\section{Acknowledgements}

This work was supported by grant 52400-F and 39525-M and fellowship 203588 to MNJG from CONACYT-México. We thank A. Serna-Juárez for the mechanical design of the electromagnetic field equipment and Dr. M. Hernández for providing antibody anti-actin as well as E. Arce-Popoca, S. Hernández-García, L. Alemán-Lazarini and S. Fattel-Fazenda for their technical assistance. We also express our gratitude to Dr. J. Fernández and R. LeyvaMuñoz for assistance with animal care and handling. The authors acknowledge the support of Dr. I. Hernández-Calderón.

\section{Author Details}

1Department of Physics Center of Research and Advanced Studies of the National Polytechnic Institute, Mexico City, Mexico and 2Department of Cell Biology, Center of Research and Advanced Studies of the National Polytechnic Institute, Mexico City, Mexico

Received: 22 October 2009 Accepted: 24 April 2010

Published: 24 April 2010

\section{References}

1. Repacholi MH, Greenebaum B: Interaction of static and extremely low frequency electric and magnetic fields with living systems: health effects and research needs. Bioelectromagnetics 1999, 20(3):133-160.

2. Girgert R, Schimming H, Korner W, Grundker C, Hanf V: Induction of tamoxifen resistance in breast cancer cells by ELF electromagnetic fields. Biochem Biophys Res Commun 2005, 336(4):1144-1149.

3. Chen G, Upham BL, Sun W. Chang CC, Rothwell EJ, Chen KM, Yamasaki H, Trosko JE: Effect of electromagnetic field exposure on chemically induced differentiation of friend erythroleukemia cells. Environ Health Perspect 2000, 108(10):967-972.

4. Barbault A, Costa FP, Bottger B, Munden RF, Bomholt F, Kuster N, Pasche B: Amplitude-modulated electromagnetic fields for the treatment of cancer: discovery of tumor-specific frequencies and assessment of a novel therapeutic approach. J Exp Clin Cancer Res 2009, 28:51.

5. Galloni P, Marino C: Effects of $50 \mathrm{~Hz}$ magnetic field exposure on tumo experimental models. Bioelectromagnetics 2000, 21(8):608-614

6. Yasui M, Kikuchi T, Ogawa M, Otaka Y, Tsuchitani M, Iwata H: Carcinogenicity test of $50 \mathrm{~Hz}$ sinusoidal magnetic fields in rats. Bioelectromagnetics 1997, 18(8):531-540.

7. Williams CD, Markov MS, Hardman WE, Cameron IL: Therapeutic electromagnetic field effects on angiogenesis and tumor growth. Anticancer Res 2001, 21(6A):3887-3891.

8. Cameron IL, Sun LZ, Short N, Hardman WE, Williams CD: Therapeutic Electromagnetic Field (TEMF) and gamma irradiation on human breast cancer xenograft growth, angiogenesis and metastasis. Cancer Cell Int 2005, 5:23.

9. Rannug A, Holmberg B, Ekstrom T, Mild KH: Rat liver foci study on coexposure with $50 \mathrm{~Hz}$ magnetic fields and known carcinogens. Bioelectromagnetics 1993, 14(1):17-27.

10. Carrasco-Legleu CE, Marquez-Rosado L, Fattel-Fazenda S, Arce-Popoca E, Perez-Carreon JI, Villa-Trevino S: Chemoprotective effect of caffeic acid phenethyl ester on promotion in a medium-term rat hepatocarcinogenesis assay. Int J Cancer 2004, 108(4):488-492.

11. Arellanes-Robledo J, Marquez-Rosado L, Perez-Carreon Jl, Fattel-Fazenda S, Aguirre-Garcia J, Villa-Trevino S: Celecoxib induces regression of putative preneoplastic lesions in rat liver. Anticancer Res 2006 26(2A):1271-1280

12. Marquez-Rosado L, Trejo-Solis MC, Garcia-Cuellar CM, Villa-Trevino S: Celecoxib, a cyclooxygenase- 2 inhibitor, prevents induction of liver preneoplastic lesions in rats. J Hepatol 2005, 43(4):653-660. 
13. Semple-Roberts E, Hayes MA, Armstrong D, Becker RA, Racz WJ, Farber E: Alternative methods of selecting rat hepatocellular nodules resistant to 2-acetylaminofluorene. Int J Cancer 1987, 40(5):643-645.

14. Rutenburg AM, Kim H, Fischbein JW, Hanker JS, Wasserkrug HL, Seligman AM: Histochemical and ultrastructural demonstration of gammaglutamyl transpeptidase activity. J Histochem Cytochem 1969, 17(8):517-526.

15. Kelman Z: PCNA: structure, functions and interactions. Oncogene 1997, 14(6):629-640.

16. Scholzen T, Gerdes J: The Ki-67 protein: from the known and the unknown. J Cell Physiol 2000, 182(3):311-322.

17. Mann CD, Neal CP, Garcea G, Manson MM, Dennison AR, Berry DP: Prognostic molecular markers in hepatocellular carcinoma: a systematic review. Eur J Cancer 2007, 43(6):979-992.

18. Donnellan R, Chetty R: Cyclin D1 and human neoplasia. Mol Pathol 1998, 51(1):1-7

19. Hanahan D, Weinberg RA: The hallmarks of cancer. Cell 2000, 100(1):57-70.

20. Perez-Carreon Jl, Lopez-Garcia C, Fattel-Fazenda S, Arce-Popoca E, Aleman-Lazarini L, Hernandez-Garcia S, Le Berre V, Sokol S, Francois JM, Villa-Trevino S: Gene expression profile related to the progression of preneoplastic nodules toward hepatocellular carcinoma in rats. Neoplasia 2006, 8(5):373-383.

21. Mi Y, Sun C, Yao C, Li C, Mo D, Tang L, Liu H: Effects of steep pulsed electric fields (SPEF) on mitochondrial transmembrane potential of human liver cancer cell. Conf Proc IEEE Eng Med Biol Soc 2007, 2007:5815-5818.

22. de Seze R, Tuffet S, Moreau JM, Veyret B: Effects of $100 \mathrm{mT}$ time varying magnetic fields on the growth of tumors in mice. Bioelectromagnetics 2000, 21(2):107-111.

23. Tofani S, Barone D, Cintorino M, de Santi MM, Ferrara A, Orlassino R, Ossola P, Peroglio F, Rolfo K, Ronchetto F: Static and ELF magnetic fields induce tumor growth inhibition and apoptosis. Bioelectromagnetics 2001, 22(6):419-428.

24. Tofani S, Cintorino M, Barone D, Berardelli M, De Santi MM, Ferrara A, Orlassino R, Ossola P, Rolfo K, Ronchetto F, Tripodi SA, Tosi P: Increased mouse survival, tumor growth inhibition and decreased immunoreactive p53 after exposure to magnetic fields. Bioelectromagnetics 2002, 23(3):230-238.

25. Jian W, Wei Z, Zhiqiang C, Zheng F: X-ray-induced apoptosis of BEL-7402 cell line enhanced by extremely low frequency electromagnetic field in vitro. Bioelectromagnetics 2009, 30(2):163-165.

26. Lange S, Viergutz T, Simko M: Modifications in cell cycle kinetics and in expression of $\mathrm{G} 1$ phase-regulating proteins in human amniotic cells after exposure to electromagnetic fields and ionizing radiation. Cell Prolif 2004, 37(5):337-349.

27. Xiong $Y$, Zhang $H$, Beach D: D type cyclins associate with multiple protein kinases and the DNA replication and repair factor PCNA. Cell 1992, 71(3):505-514

28. Kanoh M, Takemura G, Misao J, Hayakawa Y, Aoyama T, Nishigaki K, Noda T, Fujiwara T, Fukuda K, Minatoguchi S, Fujiwara H: Significance of myocytes with positive DNA in situ nick end-labeling (TUNEL) in hearts with dilated cardiomyopathy: not apoptosis but DNA repair. Circulation 1999, 99(21):2757-2764.

29. Bertagnolli MM, Eagle CJ, Zauber AG, Redston M, Solomon SD, Kim K, Tang J, Rosenstein RB, Wittes J, Corle D, Hess TM, Woloj GM, Boisserie F, Anderson WF, Viner JL, Bagheri D, Burn J, Chung DC, Dewar T, Foley TR, Hoffman N, Macrae F, Pruitt RE, Saltzman JR, Salzberg B, Sylwestrowicz T, Gordon GB, Hawk ET: Celecoxib for the prevention of sporadic colorectal adenomas. N Engl J Med 2006, 355(9):873-884

30. Robertson JA, Thomas AW, Bureau Y, Prato FS: The influence of extremely low frequency magnetic fields on cytoprotection and repair. Bioelectromagnetics 2007, 28(1):16-30.

31. DiCarlo AL, Farrell JM, Litovitz TA: Myocardial protection conferred by electromagnetic fields. Circulation 1999, 99(6):813-816.

32. Blank M, Soo L: Electromagnetic acceleration of electron transfer reactions. J Cell Biochem 2001, 81(2):278-283.

33. Panagopoulos DJ, Karabarbounis A, Margaritis LH: Mechanism for action of electromagnetic fields on cells. Biochem Biophys Res Commun 2002 298(1):95-102.
34. Strauch B, Herman C, Dabb R, Ignarro LJ, Pilla AA: Evidence-based use of pulsed electromagnetic field therapy in clinical plastic surgery. Aesthet Surg J 2009, 29(2):135-143

35. Berridge MJ, Bootman MD, Roderick HL: Calcium signalling: dynamics, homeostasis and remodelling. Nat Rev Mol Cell Biol 2003, 4(7):517-529.

36. Berridge MJ, Lipp P, Bootman MD: The versatility and universality of calcium signalling. Nat Rev Mol Cell Biol 2000, 1(1):11-21.

37. El-Serag HB, Rudolph KL: Hepatocellular carcinoma: epidemiology and molecular carcinogenesis. Gastroenterology 2007, 132(7):2557-2576.

\section{Pre-publication history}

The pre-publication history for this paper can be accessed here: http://www.biomedcentral.com/1471-2407/10/159/prepub

doi: 10.1186/1471-2407-10-159

Cite this article as: Jiménez-García et al., Anti-proliferative effect of extremely low frequency electromagnetic field on preneoplastic lesions formation in the rat liver BMC Cancer 2010, 10:159

\section{Submit your next manuscript to BioMed Centra and take full advantage of:}

- Convenient online submission

- Thorough peer review

- No space constraints or color figure charges

- Immediate publication on acceptance

- Inclusion in PubMed, CAS, Scopus and Google Scholar

- Research which is freely available for redistribution

Submit your manuscript at www.biomedcentral.com/submit
C Biomed Central 